\title{
Políticas públicas de saúde para deficientes intelectuais no Brasil: uma revisão integrativa
}

\author{
Public health policies for the intellectually disabled in Brazil: \\ an integrative review
}

\author{
Rodrigo Victor Viana Tomaz ${ }^{1}$ \\ Thiago Lusivo Rosa ${ }^{1}$ \\ David Bui Van ${ }^{1}$ \\ Débora Gusmão Melo ${ }^{1}$
}

\footnotetext{
${ }^{1}$ Departamento de Medicina, Universidade Federal de São Carlos. Rod. Washington Luís Km 235, Campus da UFSCar. São Carlos, SP, Brasil. dgmelo@ufscar.br
}

\begin{abstract}
This study presents an integrative review of the scientific literature and federal legislation on public health policies for intellectually disabled in Brazil. Nine articles, published in the PubMed, Scopus, Virtual Health Library and Web of Science databases between 2002 and 2012, were selected. Based on the references of these studies, 6 other articles were identified, totaling 15 studies in the review. Forty-one federal laws produced between 2002 and 2012 were identified. The documents were analyzed and categorized according to the main themes of socioeconomic conditions, violence, mental health, ethics, health needs, health promotion and prevention. From the scientific standpoint, non-specific discussions were observed where intellectual disability was examined with other types of handicaps or concomitantly with other Latin American countries. From the legal standpoint, although laws related to health have been located, there is a lack of studies that address the effectiveness and level of implementation of the proposed policies. The increase in research in this area is a demand of the disabled population itself, and will reveal their specific health needs, and will also support issues such as prevention, promotion, diagnosis and treatment.

Key words Intellectual handicap, Public policies, Health policy, Review
\end{abstract}

Resumo Este estudo apresenta revisão integrativa da literatura científica e da legislação federal sobre políticas públicas de saúde para deficientes intelectuais no Brasil. Foram selecionados 9 artigos veiculados nas bases PubMed, Scopus, Biblioteca Virtual de Saúde e Web of Science entre 2002 e 2012. A partir das referências bibliográficas desses estudos, foram identificados outros 6 artigos, totalizando 15 na revisão. Foram identificadas 41 legislações federais produzidas entre 2002 e 2012. Os documentos foram analisados e categorizados em condições socioeconômicas, violência, saúde mental, ética, necessidades de saúde, promoção e prevenção da saúde. Do ponto de vista científico, observou-se discussões pouco específicas, sendo a deficiência intelectual examinada com os demais tipos ou em concomitância com outros países da América Latina. Do ponto de vista jurídico, embora tenham sido localizadas legislações relacionadas à área da saúde, faltam estudos que abordem a efetividade e o nível de implantação das políticas propostas. O incremento de pesquisas na área é demanda da própria população deficiente e permitirá conhecer suas necessidades de saúde específicas, além de oferecer embasamento em questões como prevenção, promoção, diagnóstico e tratamento.

Palavras-chave Deficiência intelectual, Politicas públicas, Política de saúde, Revisão 


\section{Introdução}

Deficiência intelectual (DI) é resultado do funcionamento intelectual inferior à média, que aparece antes dos 18 anos, acompanhado de limitações no funcionamento adaptativo em, pelo menos, duas das seguintes áreas: comunicação, autocuidado, vida doméstica, relações sociais/ interpessoais, uso de recursos comunitários, autossuficiência, habilidades acadêmicas, trabalho, lazer, saúde e seguranç ${ }^{1,2}$. Do ponto de vista clínico, DI é sinal de mais de 2.000 condições, incluindo muitas doenças genéticas raras². Dados do Censo de 2010 indicam que 1,4\% da população brasileira possui $\mathrm{DI}^{3}$.

Em 2002 foi publicada a Política Nacional de Saúde da Pessoa Portadora de Deficiência, marco histórico para reflexão acerca das ações de saúde para essa população $0^{4}$. Conferências Nacionais sobre os Direitos da Pessoa com Deficiência foram realizadas nos anos de 2006, 2008 e $2012^{5}$. Quatro eixos temáticos orientaram as discussões: (1) educação, esporte, trabalho e reabilitação profissional; (2) acessibilidade, comunicação, transporte e moradia; (3) saúde, prevenção, reabilitação, órteses e próteses; (4) segurança, acesso à justiça, padrão de vida e proteção social ${ }^{6}$. $\mathrm{Na}$ área da saúde, na última Conferência, foram aprovadas 91 propostas, que incluem aspectos como: aperfeiçoamento dos sistemas de acesso a serviços, medicamentos e tecnologias de saúde; capacitação de profissionais para atendimento multiprofissional e humanizado; implantação de centros de referência destinados à população deficiente; cumprimento de estratégias de promoção, prevenção e monitorização; ampliação, fomentação e divulgação de pesquisas científicas relacionadas ao tema ${ }^{6}$. Espera-se que as ações e os programas desenhados pelo Estado brasileiro se orientem pelas deliberações dessas Conferências.

No Brasil, durante décadas, o referencial assistencial para deficientes intelectuais esteve quase que totalmente restrito a instituições de caráter filantrópico e organizações não governamentais ${ }^{7}$. Nesse contexto, destaca-se a rede formada pelas Associações de Pais e Amigos dos Excepcionais (APAE), composta por mais de duas mil unidades distribuídas no país e que atualmente atendem cerca de 250.000 pessoas. Nessa área de atuação, o maior movimento social do Brasil é o Apaeano ${ }^{8}$, o qual contribuiu de forma inequívoca nos avanços de diferentes políticas públicas, especialmente aquelas relacionadas à educação, trabalho, habitação e assistência social. Percebese, porém, que não houve avanços na mesma di- mensão na formulação das políticas públicas de saúde para deficientes intelectuais.

Estima-se que mais de um terço dos deficientes intelectuais têm associados diagnósticos de transtornos mentais, prevalência que justifica o debate internacional sobre ambos temas conjuntamente, tendo esse diagnóstico dual se configurado recentemente como um novo objeto de investigação ${ }^{9}$. No Brasil, a saúde mental consolidou-se como política pública de Estado, organizada por uma rede de serviços que tem como "carro chefe" os Centros de Atenção Psicossocial (CAPS). Embora os deficientes intelectuais representem uma parcela importante da população atendida nos CAPS, nem sempre este local reconhece e maneja adequadamente suas necessidades de saúde particulares. O desafio da inclusão social do deficiente intelectual depende da garantia dos direitos à saúde e à prevenção de agravos, e o impacto dos problemas de saúde mental pode reduzir significativamente suas possibilidades nessa área, questão que talvez esteja subestimada no país ${ }^{7,9}$.

Especificamente relacionado ao cuidado em saúde dos deficientes intelectuais, há a Portaria N.o 199 do Ministério da Saúde, publicada em 2014, e que instituiu a Política Nacional de Atenção Integral às Pessoas com Doenças Raras no âmbito do SUS ${ }^{10}$. Nessa Política, previu-se que a atenção das pessoas com doenças raras seria estruturada em dois eixos e, no caso das doenças raras de origem genética, haveria uma linha de cuidado desenhada especialmente para pessoas com $\mathrm{DI}^{10}$. O fluxograma de atendimento recomendado enfatiza a busca por um diagnóstico etiológico, muitas vezes genético e sindrômi$\mathrm{Co}^{11}$. É importante reconhecer a importância da dimensão biomédica da DI e, inclusive, considerar a possibilidade de aconselhamento genético familiar como ação em saúde; contudo, é fundamental ressaltar que o desafio do cuidado em saúde do deficiente intelectual abrange, para além da perspectiva biológica, aspectos sociais e ambientais.

O objetivo dessa pesquisa foi realizar revisão integrativa sobre políticas públicas de saúde para deficientes intelectuais no Brasil, visando a contribuir para a síntese e a identificação de lacunas de conhecimento. As questões norteadoras foram: (a) o que foi produzido cientifica e juridicamente sobre o assunto desde a publicação da Política Nacional de Saúde da Pessoa Portadora de Deficiência em 2002?; e, (b) quais demandas de assistência e pesquisa são observadas na área? 


\section{Metodologia}

\section{Identificação, seleção e análise dos artigos}

A pesquisa foi conduzida em 2013, por meio de consulta às bases bibliográficas eletrônicas Medline/PubMed, Biblioteca Virtual de Saúde (BVS), Scopus e Web of Science.

Os descritores empregados foram obtidos a partir do DeCS - "Descritores em Ciências da Saúde" ou do MeSH - "Medical Subject Headings". Em língua portuguesa foram: (retardo mental OR retardamento mental OR deficiência mental OR deficiência intelectual) AND (políticas públicas OR política de saúde OR participação cidadã OR direitos das pessoas portadoras de deficiência OR direitos dos deficientes). Em língua inglesa foram: (mental retardation $\mathrm{OR}$ mental deficiency OR intellectual disability OR mentally disabled persons OR mentally retarded) AND (public policies OR health policy OR citizen participation $\mathrm{OR}$ patient rights $\mathrm{OR}$ rights $\mathrm{OR}$ handicapped advocacy).

De acordo com critérios pré-definidos, seriam escolhidos apenas artigos sobre políticas públicas de saúde para deficientes intelectuais no Brasil, publicados em português ou inglês e indexados nas bases de dados entre 2002 e 2012. Como provavelmente haveria um pequeno número de estudos satisfazendo os critérios de inclusão, optou-se por também inserir artigos que: (1) não tratassem exclusivamente da DI - discutindo as deficiências de um modo geral, incluindo a DI, como as físicas e sensoriais; (2) abordassem o tema em países de rendimento médio - classificação econômica que abrange o Brasil ${ }^{12}$; (3) fossem sobre desordens mentais ou políticas de saúde mental - desde que considerassem a DI em suas análises.

Foram excluídos os artigos que abordavam DI sob outras perspectivas e os textos repetidos nas bases de dados. Para tratar as duplicidades de artigos recuperados nas diferentes bases, os documentos originalmente encontrados em cada uma delas foram ordenados por título e autoria, sendo excluídos aqueles que apareciam mais de uma vez.

Três pesquisadores realizaram as buscas nas bases de dados de forma independente. Os artigos inicialmente identificados foram analisados a partir dos títulos e resumos, realizando-se uma primeira exclusão. Após essa exclusão, foi elaborada uma lista dos artigos selecionados. Todos estes foram considerados relevantes, lidos integralmente pelos pesquisadores e submetidos a uma segunda etapa de exclusão, considerando-se os critérios de elegibilidade. Divergências foram resolvidas por consenso, depois de nova crítica do artigo em questão, incluindo um quarto revisor. As referências bibliográficas dos artigos selecionados foram revisadas manualmente procurando-se trabalhos adicionais relevantes que não houvessem sido identificados através da estratégia de busca.

A partir da análise das produções científicas selecionadas, os dados foram categorizados por aproximação temática.

\section{Avaliação do nível de evidência dos artigos}

O nível de evidência dos artigos foi atribuído com base na classificação proposta por Melnyk e Fineout-Overholt ${ }^{13}$. As evidências seriam: nível 1 - de revisão sistemática ou metanálise de todos os ensaios clínicos randomizados controlados relevantes ou provenientes de diretrizes clínicas baseadas em revisões sistemáticas destes; nível 2 - de pelo menos um ensaio clínico randomizado controlado bem delineado; nível 3 - de ensaios clínicos bem delineados sem randomização; nível 4 - de estudo de coorte e de caso-controle bem delineados; nível 5 - de revisão sistemática de estudos descritivos e qualitativos; nível 6 - de um único estudo descritivo ou qualitativo; nível 7 - de opinião de autoridades e/ou relatórios de comitê de especialistas.

\section{Identificação, seleção e análise das legislações}

Realizou-se busca de legislações federais produzidas entre 2002 e 2012 na versão brasileira do Google Search, empregando-se os termos: (retardo mental OR retardamento mental OR deficiência mental OR deficiência intelectual) AND (decreto OR lei OR portaria OR resolução).

Foram incluídas legislações federais sancionadas que versassem sobre DI do ponto de vista da saúde, incluindo textos que abordassem incentivos financeiros, programas de triagem e protocolos clínicos para doenças que cursam com DI.

Foram excluídas as legislações sem relação com a área da saúde, as municipais ou estaduais e os projetos de leis.

Este corpo documental passou por análise criteriosa, a fim de apreender a temática principal e realizar categorização por linhas de convergência. 


\section{Resultados}

O processo de busca e seleção dos artigos científicos resultou no total de nove artigos. A partir da análise das referências bibliográficas desses estudos, foram identificados e incluídos mais seis artigos que versavam sobre a temática desta revisão (Figura 1).

Um estudo ${ }^{14}(6,7 \%)$ é uma revisão sistemática de ensaios clínicos randomizados controlados, com nível de evidência 1 . Outro ${ }^{15}(6,7 \%)$ apresentou nível de evidência 2 por se tratar de revisão sistemática que inclui três ensaios clínicos randomizados. Duas revisões sistemáticas de literatura ${ }^{16,17}(13,3 \%)$ apresentaram nível de evidência 5 , por incluir apenas estudos descritivos. Oito $(53,3 \%)$ são estudos de natureza descritiva e apresentaram nível de evidência 6 , sendo: quatro ${ }^{18-21}(26,7 \%)$ revisões não sistemáticas, dois $^{22,23}(13,3 \%)$ quantitativos, não experimentais e transversais, e dois ${ }^{24,25}$ (13,3\%) qualitativos. Três ${ }^{26-28}(20 \%)$ são reflexões de especialistas e obtiveram nível de evidência 7 .

Quatro estudos ${ }^{14,15,19,21}(26,7 \%)$ são conduzidos por autores não brasileiros e cinco ${ }^{14,15,17,19,21}$ dos 15 artigos $(33,3 \%)$ foram publicados em periódicos internacionais.

Políticas de saúde para pessoas com DI no Brasil são discutidas em artigos que incluem os demais países da América Latina ${ }^{17,21,27}$ ou que abordam a questão em países de rendimento baixo e médio ${ }^{14,15,19}$. Quando retratam exclusivamente o contexto brasileiro, os textos não focam unicamente DI, abordando também outras deficiências (físicas, visuais e auditivas) ${ }^{16,23,26}$, ou ainda, discutem políticas de saúde mental ${ }^{20}$. Dois artigos ${ }^{18,22}$ retratam a atenção aos defeitos congênitos e doenças genéticas no Brasil, consi-

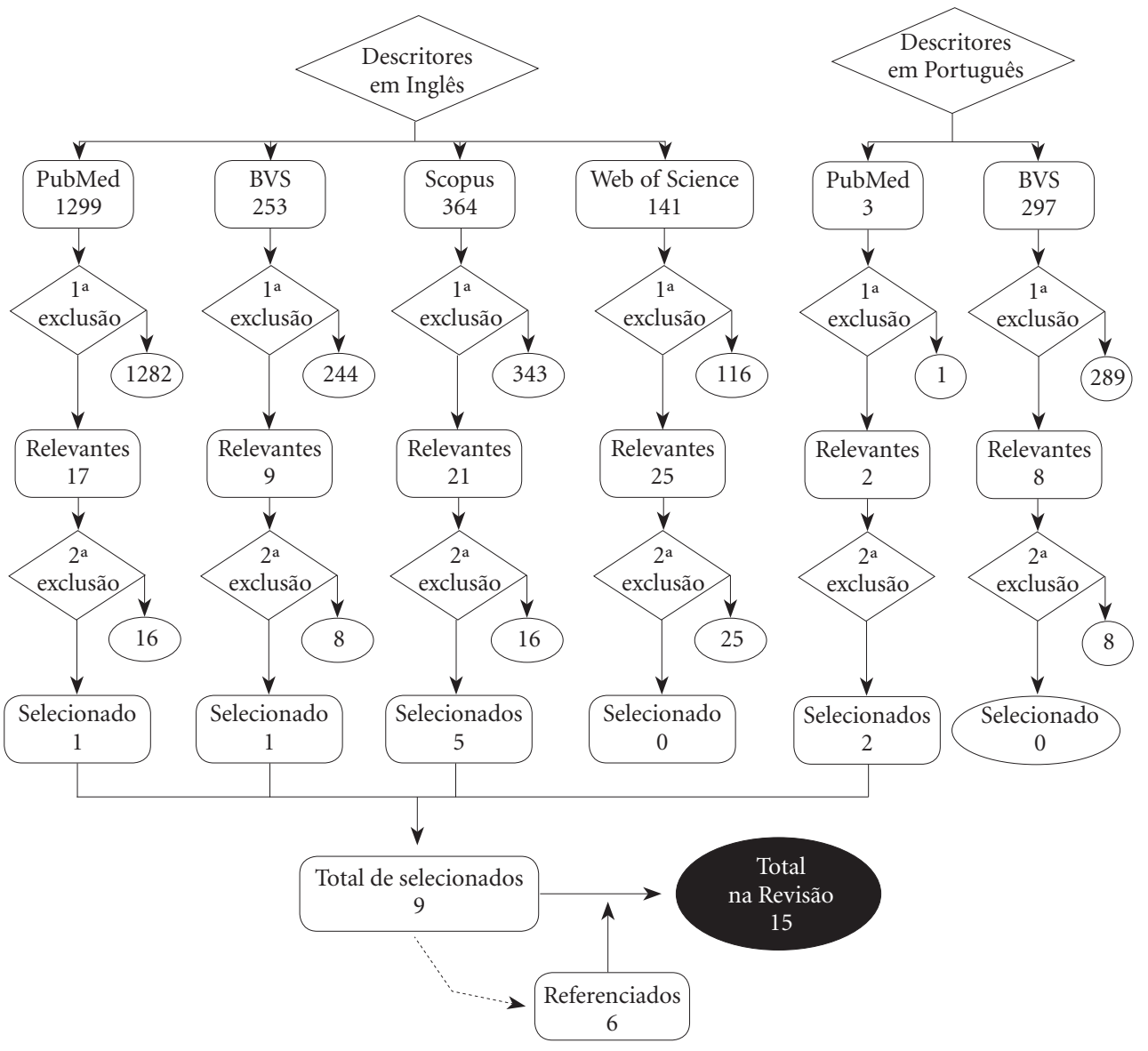

Figura 1. Descrição da seleção dos estudos. 
derando que DI é frequentemente associada a essas condições. Há ainda um artigo ${ }^{25}$ que explora as tradições culturais nos discursos de médicos, acerca de crianças com doenças genéticas associadas a malformações congênitas e DI, por meio de pesquisa qualitativa. Três publicações ${ }^{24,27,28}$ estabelecem paralelo entre pobreza, violência e deficiência.

O Quadro 1 apresenta uma síntese com os resultados mais relevantes apreendidos a partir da análise dos 15 artigos.

A busca das legislações resultou em 41 documentos: cinco decretos, três leis, 28 portarias e cinco resoluções. A maior parte dessas legislações objetiva garantir direitos à população com alguma deficiência, não sendo voltada exclusivamente para deficientes intelectuais. Foram encontradas apenas duas resoluções federais direcionadas especificamente a este público: uma aborda o atendimento a "portadores de retardo mental" e outra diretrizes de atenção à pessoa com síndrome de Down. Há também portarias e leis cujos textos versam sobre triagem neonatal e protocolos clínicos para condições que podem cursar com DI, como rubéola congênita e transtorno de espectro autista. Os temas abordados pelas legislações são apresentados no Quadro 2.

\section{Discussão}

Seis categorias temáticas, discutidas a seguir, foram apreendidas a partir da análise dos 15 artigos e das 41 legislações federais.

\section{Condições socioeconômicas}

A relação entre baixo nível socioeconômico e DI parece implicar em maior prevalência deste tipo de deficiência em países da América Latina. Entre crianças do Brasil, as vítimas da pobreza são três vezes mais acometidas por problemas de desenvolvimento ${ }^{27}$.

Deficientes intelectuais convivem com estigmas e uma vida marginalizada ${ }^{15}$. Gera-se um ciclo "deficiência-pobreza-deficiência", onde a marginalização ocasiona menor acesso a boas condições de trabalho, saúde e educação, fatores decisivos no estabelecimento e na manutenção da deficiência ${ }^{27}$.

Os baixos investimentos dos países de baixa e média renda em promoção de saúde acarretam diretamente na maior exposição a fatores de risco conhecidos para DI, como desnutrição, exposição materna a teratógenos, pré-natal inadequa- $\mathrm{do}^{17}$, deficiência de iodo, trauma e asfixia durante o nascimento ${ }^{15}$.

A pobreza implica em menor capacidade de utilizar serviços públicos, em privações, exclusão e menor participação social ${ }^{27}$, comprometendo o exercício da cidadania. É determinante na menor qualidade de vida da população brasileira com DI, em comparação a daquelas de países economicamente desenvolvidos, justamente pelo menor acesso à saúde e educação ${ }^{17}$. Estudo realizado com 117 pessoas com deficiência no município de Sobral, Ceará, por exemplo, observou que grande parte dos indivíduos possuía baixa escolaridade $(75,21 \%$ de analfabetismo) e baixo rendimento financeiro $(42,74 \%$ sem rendimento formal $)^{23}$.

Disparidades sociais historicamente construídas influenciam diretamente no cuidado em saúde da população com DI e, nesse sentido, é provável que no Brasil, entre os cidadãos com essa deficiência, os negros tenham ainda menor acesso a serviços de saúde do que os brancos ${ }^{21}$.

Nesta revisão, foram identificadas 4 portarias federais que tratam especificamente de incentivo financeiro e transferência de recursos para instituições envolvidas no cuidado à pessoas com DI (Quadro 2).

A transferência de recursos diretamente aos deficientes é garantida desde 1993 pela Lei no $8.742^{29}$, que sanciona o benefício da prestação continuada. Para pleitear esse benefício, a renda familiar per capita não deve ser superior a $25 \%$ do salário mínimo. Com um ponto de corte baixo, muitos deficientes não têm acesso ao benefício, embora tenham necessidades reais, devido, principalmente, aos custos envolvidos com tratamento e reabilitação.

\section{Violência}

Pobreza e desigualdade social configuram importantes fatores preditivos para violência. Indivíduos com deficiência estão particularmente vulneráveis, possuindo risco 4 a 10 vezes superior de sofrerem violência quando comparados aos demais indivíduos ${ }^{28}$. Dessa forma, a questão da proteção adequada contra violência deve ser preocupação das instituições que trabalham com $\mathrm{DI}^{24}$.

Pesquisas sobre deficiência e violência no Brasil são escassas. Destaca-se o trabalho de Cavalcante et al. ${ }^{24}$, uma investigação qualitativa conduzida em três instituições de assistência no Rio de Janeiro, envolvendo 53 estudos de caso, que objetivou analisar como elas lidavam com situações de violência e violação de direitos con- 
Quadro 1. Categorização dos artigos sobre políticas públicas de saúde para deficientes intelectuais no Brasil, no período entre 2002 e 2012.

\begin{tabular}{|c|c|c|c|c|}
\hline Artigo & Objetivos & Metodologia & Principais resultados & NE \\
\hline $\begin{array}{l}\text { Patel et al., } \\
2007^{14} \text {. }\end{array}$ & $\begin{array}{l}\text { Revisar a evidência } \\
\text { da efetividade dos } \\
\text { ensaios clínicos } \\
\text { relacionados a } \\
\text { tratamento e } \\
\text { prevenção de } \\
\text { distúrbios mentais } \\
\text { em países de } \\
\text { rendimento médio } \\
\text { e baixo. }\end{array}$ & $\begin{array}{l}\text { Revisão sistemática de } \\
\text { literatura. Busca nas } \\
\text { bases de dados PsiTri, } \\
\text { Cochrane Library, } \\
\text { PsycInfo, Medline e } \\
\text { PubMed com descritores } \\
\text { específicos. }\end{array}$ & $\begin{array}{l}\text { Foram identificados } 11.501 \text { ensaios clínicos, } \\
\text { dentre os quais } 1.104 \text { procedentes de países de } \\
\text { rendimento baixo e médio e } 12 \text { envolvendo } \\
\text { deficiências no desenvolvimento, entre } \\
\text { elas a DI. As evidências sobre a eficácia } \\
\text { das intervenções para as deficiências são } \\
\text { inadequadas, porém, para o cuidado de adultos } \\
\text { e de crianças com DI, modelos de reabilitação } \\
\text { baseados na comunidade parecem mais } \\
\text { adequados e de baixo custo. São necessárias } \\
\text { pesquisas sobre a qualidade dos serviços já } \\
\text { prestados. Recomenda-se que os gestores } \\
\text { de saúde se debrucem sobre as evidências } \\
\text { científicas para escalonar a efetividade e o } \\
\text { custo-benefício das ações de tratamento e } \\
\text { prevenção dos distúrbios mentais. }\end{array}$ & 1 \\
\hline $\begin{array}{l}\text { Maulik e } \\
\text { Darmstadt, } \\
2007^{15} \text {. }\end{array}$ & $\begin{array}{l}\text { Mapear o } \\
\text { conhecimento } \\
\text { atual sobre crianças } \\
\text { com deficiência } \\
\text { em países de } \\
\text { rendimento médio } \\
\text { e baixo, e identificar } \\
\text { lacunas para guiar } \\
\text { pesquisas futuras. }\end{array}$ & $\begin{array}{l}\text { Revisão sistemática de } \\
\text { literatura. Busca nas } \\
\text { bases de dados PubMed, } \\
\text { Embase, PsycInfo e } \\
\text { Cochrane Library, com } \\
\text { descritores específicos } \\
\text { obtidos do MeSH, } \\
\text { limitando-se a textos que } \\
\text { abordassem a infância } \\
(0-12 \text { anos). }\end{array}$ & $\begin{array}{l}\text { Foram selecionados } 8 \text { estudos, incluindo } 3 \\
\text { ensaios clínicos randomizados. É escassa a } \\
\text { pesquisa sobre a deficiência na infância nos } \\
\text { países de rendimento médio e baixo. Foram } \\
\text { notados estudos de qualidade inadequada. } \\
\text { Os estudos epidemiológicos foram os mais } \\
\text { realizados, e as condições mais estudadas } \\
\text { foram as deficiências auditiva e intelectual. } \\
\text { Informações sobre intervenções específicas e } \\
\text { utilização de serviços e legislações são escassas. } \\
\text { Faltam dados sobre morbidade perinatal. }\end{array}$ & 2 \\
\hline $\begin{array}{l}\text { França et al., } \\
2008^{16} \text {. }\end{array}$ & $\begin{array}{l}\text { Investigar o } \\
\text { impacto da Política } \\
\text { Nacional para } \\
\text { a Integração da } \\
\text { Pessoa Portadora } \\
\text { de Deficiência no } \\
\text { Brasil e os aspectos } \\
\text { evidentes no } \\
\text { discurso acadêmico } \\
\text { sobre o assunto. }\end{array}$ & $\begin{array}{l}\text { Revisão sistemática de } \\
\text { literatura. Busca nas } \\
\text { bases de dados Lilacs, } \\
\text { Medline, Cochrane, e } \\
\text { SciELO, utilizando-se } \\
\text { descritores específicos: } \\
\text { "políticas públicas", } \\
\text { "inclusão social", } \\
\text { "deficiente" e "cidadania". }\end{array}$ & $\begin{array}{l}\text { Foram selecionados } 135 \text { textos versando sobre } \\
\text { políticas públicas, } 18 \text { sobre inclusão social, } \\
132 \text { sobre deficiente e } 261 \text { acerca de cidadania. } \\
\text { Pessoas com deficiência conquistaram políticas } \\
\text { que asseguram acesso a bens e serviços, mas } \\
\text { encontram dificuldades de inclusão nos } \\
\text { campos da educação e do mercado de trabalho, } \\
\text { devido à pouca instrução, desqualificação e } \\
\text { resistência por parte das empresas. O discurso } \\
\text { acadêmico elucida entraves na inclusão, } \\
\text { priorizando direitos à educação, mercado de } \\
\text { trabalho e assistência à saúde, em detrimento } \\
\text { de direitos relativos à cultura, turismo e lazer. }\end{array}$ & 5 \\
\hline $\begin{array}{l}\text { Mercadante } \\
\text { et al., } 2009^{17} \text {. }\end{array}$ & $\begin{array}{l}\text { Resumir os } \\
\text { dados sobre } \\
\text { DI na América } \\
\text { Latina, publicados } \\
\text { em periódicos } \\
\text { científicos e } \\
\text { disponíveis em } \\
\text { sites oficiais. } \\
\text { Discutir possíveis } \\
\text { implicações desses } \\
\text { estudos em políticas } \\
\text { e serviços de saúde. }\end{array}$ & $\begin{array}{l}\text { Revisão sistemática de } \\
\text { literatura. Buscas nas } \\
\text { bases de dados Medline, } \\
\text { Scielo e Lilacs, entre 2004 } \\
\text { e 2009, com descritores } \\
\text { específicos obtidos do } \\
\text { MeSH. Foram realizadas } \\
\text { buscas adicionais de } \\
\text { acordo com os principais } \\
\text { autores e revistas } \\
\text { científicas da América } \\
\text { Latina. }\end{array}$ & $\begin{array}{l}\text { Foram selecionados } 33 \text { artigos, sendo que } 8 \\
\text { tratavam do Brasil. A subnutrição, o cuidado } \\
\text { puerperal precário e a exposição a infecções, } \\
\text { comuns nos países da América Latina podem } \\
\text { contribuir para uma maior prevalência de } \\
\text { DI. Faltam estudos locais, o que dificulta a } \\
\text { avaliação e o desenvolvimento de políticas } \\
\text { e serviços, bem como a caracterização } \\
\text { epidemiológica dos diferentes países com } \\
\text { relação à DI, tornando difícil também o } \\
\text { conhecimento das reais necessidades dos } \\
\text { deficientes. }\end{array}$ & 5 \\
\hline
\end{tabular}




\begin{tabular}{|c|c|c|c|c|}
\hline \multicolumn{5}{|c|}{ Quadro 1. continuação } \\
\hline Artigo & Objetivos & Metodologia & Principais resultados & NE \\
\hline $\begin{array}{l}\text { Horovitz et } \\
\text { al., } 2005^{18} \text {. }\end{array}$ & $\begin{array}{l}\text { Determinar } \\
\text { a relevância } \\
\text { dos defeitos } \\
\text { congênitos no } \\
\text { Brasil, mapeando } \\
\text { estratégias já } \\
\text { implementadas } \\
\text { para sua } \\
\text { abordagem. }\end{array}$ & $\begin{array}{l}\text { Estudo descritivo. } \\
\text { Revisão não sistemática } \\
\text { da literatura, com } \\
\text { análise e reflexão sobre } \\
\text { ações governamentais e } \\
\text { não governamentais já } \\
\text { implantadas na área dos } \\
\text { defeitos congênitos no } \\
\text { Brasil. }\end{array}$ & $\begin{array}{l}\text { As ações governamentais apresentadas são: } \\
\text { PNTN; programas do Ministério da Saúde } \\
\text { para o tratamento de certas doenças genéticas, } \\
\text { como osteogênese imperfeita e doença de } \\
\text { Gaucher; fortificação de farinhas com ácido } \\
\text { fólico; PNI e monitoramento pela DNV. As } \\
\text { ações não governamentais são: ECLAMC, } \\
\text { SIAT e SIEIM. Os autores propõem que sejam } \\
\text { criados Centros de Referência em Genética } \\
\text { Médica para atender pacientes com DI. }\end{array}$ & 6 \\
\hline Patel, $2007^{19}$. & $\begin{array}{l}\text { Analisar a produção } \\
\text { bibliográfica sobre } \\
\text { as desordens } \\
\text { mentais mais } \\
\text { frequentes em } \\
\text { adultos de países de } \\
\text { rendimento médio } \\
\text { e baixo. }\end{array}$ & $\begin{array}{l}\text { Estudo descritivo. } \\
\text { Revisão não sistemática } \\
\text { sobre o assunto. }\end{array}$ & $\begin{array}{l}\text { As desordens mentais somam } 11,1 \% \text { do total } \\
\text { de doenças nos países de rendimento médio } \\
\text { e baixo. O autor inclui entre as desordens } \\
\text { neuropsiquiátricas a DI. Defende que pobreza, } \\
\text { baixa educação, exclusão social, diferenças de } \\
\text { gênero, conflitos e desastres são determinantes } \\
\text { para o surgimento destas desordens. } \\
\text { Intervenções comunitárias e na atenção } \\
\text { primária à saúde são efetivas no manejo das } \\
\text { desordens mentais. Apesar disso, em muitos } \\
\text { países, menos de } 1 \% \text { dos recursos destinados à } \\
\text { saúde são reservados para a saúde mental. }\end{array}$ & 6 \\
\hline $\begin{array}{l}\text { Couto et al., } \\
2008^{20} \text {. }\end{array}$ & $\begin{array}{l}\text { Analisar a } \\
\text { situação atual de } \\
\text { desenvolvimento } \\
\text { da política pública } \\
\text { brasileira de saúde } \\
\text { mental infantil } \\
\text { e juvenil, com } \\
\text { foco nos Centros } \\
\text { de Atenção } \\
\text { Psicossocial } \\
\text { Infanto-juvenil } \\
\text { (CAPSi). }\end{array}$ & $\begin{array}{l}\text { Estudo descritivo. } \\
\text { Revisão não sistemática. } \\
\text { Foram analisadas } \\
\text { publicações e dados } \\
\text { oficiais do governo } \\
\text { brasileiro sobre a } \\
\text { implantação e/ou } \\
\text { distribuição de serviços } \\
\text { públicos nacionais } \\
\text { relacionados à saúde } \\
\text { mental da criança e do } \\
\text { adolescente. }\end{array}$ & $\begin{array}{l}\text { A política de saúde mental infantil no Brasil } \\
\text { tem tido como principal ação a implementação } \\
\text { dos CAPSi. É necessário também o apoio } \\
\text { de uma rede intersetorial, envolvendo } \\
\text { saúde, educação, assistência social e direito, } \\
\text { além de articulação com outros setores } \\
\text { públicos dedicados ao cuidado da infância e } \\
\text { adolescência. }\end{array}$ & 6 \\
\hline $\begin{array}{l}\text { Frey e } \\
\text { Temple, } \\
2008^{21}\end{array}$ & $\begin{array}{l}\text { Discutir promoção } \\
\text { de saúde para } \\
\text { pessoas com DI } \\
\text { em países sul- } \\
\text { americanos. }\end{array}$ & $\begin{array}{l}\text { Estudo descritivo. } \\
\text { Revisão não sistemática. } \\
\text { Foram analisados dados } \\
\text { epidemiológicos e } \\
\text { diferentes cenários dos } \\
\text { países da América do Sul. }\end{array}$ & $\begin{array}{l}\text { Ao contrário de países desenvolvidos, os da } \\
\text { América Latina apresentam poucas iniciativas } \\
\text { para assegurar o cuidado das necessidades } \\
\text { de saúde de pessoas com DI. Não havendo } \\
\text { informação sobre a situação de saúde deste } \\
\text { segmento populacional nesses países. }\end{array}$ & 6 \\
\hline
\end{tabular}

tra crianças e adolescentes deficientes ${ }^{24}$. Nessa pesquisa, observou-se maior prevalência de negligência $(47,1 \%)$ como forma de violência, seguida por abuso psicológico (32,8\%). Menor frequência foi observada de abusos físicos (11,4\%) e sexuais $(8,6 \%)$. Encontrou-se correlação positiva entre abuso sexual, físico, violação de direitos e desordens mentais ou comportamentais, como DI e autismo, indicando dificuldade de manejo dessas situações por parte dos cuidadores ${ }^{24}$. Situações de violência física e verbal estão presentes também no contexto familiar de crianças e jovens com DI, frequentemente criticados com expressões pejorativas ${ }^{28}$. 
Quadro 1. continuação

\begin{tabular}{|c|c|c|c|c|}
\hline Artigo & Objetivos & Metodologia & Principais resultados & $\mathrm{NE}$ \\
\hline $\begin{array}{l}\text { Horovitz et } \\
\text { al., } 2006^{22} .\end{array}$ & $\begin{array}{l}\text { Mapear os serviços } \\
\text { de genética em } \\
\text { funcionamento } \\
\text { no Brasil para } \\
\text { avaliar formas de } \\
\text { integrar e otimizar } \\
\text { o atendimento aos } \\
\text { defeitos congênitos } \\
\text { e às doenças } \\
\text { genéticas no país. }\end{array}$ & $\begin{array}{l}\text { Estudo descritivo. } \\
\text { Aplicação de } \\
\text { questionário fechado, } \\
\text { censitário, visando } \\
\text { auferir e caracterizar } \\
\text { os serviços públicos } \\
\text { de genética clínica no } \\
\text { Brasil. Foram convidados } \\
\text { a participar chefes de } \\
\text { serviços de genética } \\
\text { conhecidos, professores } \\
\text { de genética de cursos } \\
\text { de medicina, membros } \\
\text { das Sociedade Brasileira } \\
\text { de Genética Clínica e } \\
\text { Sociedade Brasileira de } \\
\text { Genética. }\end{array}$ & $\begin{array}{l}\text { Quanto à localização, serviços de } 14 \text { dos } 25 \\
\text { Estados responderam à pesquisa, com menor } \\
\text { participação do norte brasileiro. Estima-se } \\
\text { que sejam realizadas } 56 \text { mil consultas anuais } \\
\text { nestes serviços. Foram encontrados problemas } \\
\text { referentes ao funcionamento dos serviços, } \\
\text { principalmente no que diz respeito ao acesso, } \\
\text { ao fluxo e à integração com a rede básica. Os } \\
\text { autores propõem que sejam criados Centros de } \\
\text { Referência em Genética Médica para atender } \\
\text { pacientes com DI. }\end{array}$ & 6 \\
\hline $\begin{array}{l}\text { Aragão et al., } \\
2010^{23} \text {. }\end{array}$ & $\begin{array}{l}\text { Traçar o perfil } \\
\text { das pessoas } \\
\text { com deficiência } \\
\text { residentes na } \\
\text { Paróquia do Cristo } \\
\text { Ressuscitado, na } \\
\text { Diocese de Sobral - } \\
\text { Ceará. }\end{array}$ & $\begin{array}{l}\text { Estudo descritivo, } \\
\text { quantitativo, transversal. } \\
\text { Realizado com } 117 \\
\text { pessoas com deficiência } \\
\text { residentes na Paróquia } \\
\text { do Cristo Ressuscitado, } \\
\text { na Diocese de Sobral - } \\
\text { Ceará. }\end{array}$ & $\begin{array}{l}\text { DI representou } 35,9 \% \text { dos casos, seguidos } \\
\text { de deficiência sensorial ( } 32,48 \%) \text { e física } \\
(27,35 \%) \text {. É necessário que os profissionais de } \\
\text { saúde conheçam a população com deficiência, } \\
\text { o que pode ser decisivo para que tais pessoas } \\
\text { tenham seus direitos garantidos. }\end{array}$ & 6 \\
\hline $\begin{array}{l}\text { Cavalcante et } \\
\text { al., } 2009^{24} \text {. }\end{array}$ & $\begin{array}{l}\text { Apresentar } \\
\text { diagnóstico } \\
\text { situacional } \\
\text { da violência } \\
\text { contra crianças } \\
\text { e adolescentes } \\
\text { com deficiência } \\
\text { e analisar como } \\
\text { três instituições de } \\
\text { referência no Rio de } \\
\text { Janeiro lidam com } \\
\text { essas situações. }\end{array}$ & $\begin{array}{l}\text { Estudo qualitativo. } \\
\text { Dados apresentados } \\
\text { a partir de } 53 \text { estudos } \\
\text { de caso, quantificados } \\
\text { unicamente para traçar } \\
\text { o perfil dos casos } \\
\text { estudados. }\end{array}$ & $\begin{array}{l}\text { Os tipos de violência mais observados foram } \\
\text { negligência, abuso físico, abuso psicológico e } \\
\text { abuso sexual, nesta ordem. Indivíduos com DI } \\
\text { e autismo foram as maiores vítimas. }\end{array}$ & 6 \\
\hline
\end{tabular}

Reflexão sobre prevenção da violência está prevista nas Conferências Nacionais de Direitos da Pessoa com Deficiência, principalmente no que diz respeito àquelas praticadas contra mulheres nessa situação ${ }^{5,6}$, cujo risco de exposição é superior a daqueles do sexo masculino. No combate à violência, é fundamental o papel do Estado na promoção de ações efetivas de proteção social.
Em março de 2007 foi realizada, na Assembleia Geral das Nações Unidas, a Convenção Internacional para Proteção e Promoção dos Direitos e Dignidade das Pessoas com Deficiência. As resoluções dessa Convenção representam importante instrumento legal no reconhecimento e na promoção dos direitos dos deficientes e na proibição da discriminação em todas as áreas da vida. 
Quadro 1. continuação

\begin{tabular}{|c|c|c|c|c|}
\hline Artigo & Objetivos & Metodologia & Principais resultados & NE \\
\hline $\begin{array}{l}\text { Martins et } \\
\text { al., } 2012^{25} \text {. }\end{array}$ & $\begin{array}{l}\text { Explorar a } \\
\text { influência de } \\
\text { tradições culturais } \\
\text { arraigadas na } \\
\text { construção do } \\
\text { discurso de médicos } \\
\text { acerca de crianças } \\
\text { com doenças } \\
\text { genéticas associadas } \\
\text { a malformações } \\
\text { congênitas e DI, } \\
\text { assim como, } \\
\text { as reflexões } \\
\text { provocadas } \\
\text { pelo convívio } \\
\text { profissional com } \\
\text { tais pacientes. }\end{array}$ & $\begin{array}{l}\text { Estudo qualitativo. } \\
\text { Dados coletados através } \\
\text { de entrevistas com } 21 \\
\text { médicos de diferentes } \\
\text { especialidades e que } \\
\text { trabalhavam no Instituto } \\
\text { Fernandes Figueira/ } \\
\text { Fiocruz há pelo menos } \\
5 \text { anos. } \\
\end{array}$ & $\begin{array}{l}\text { Nota-se que a radicalidade de ser médico } \\
\text { de uma criança deficiente faz com que haja } \\
\text { uma desorganização da experiência e da } \\
\text { explicação racional, alcançando modelos } \\
\text { explicativos pautados na religião. Enfatiza-se } \\
\text { como a concepção da família, principalmente } \\
\text { a mitificação da mãe, transformada numa } \\
\text { "heroína”, pode tornar a criança com doença } \\
\text { genética/DI “invisível", como também } \\
\text { contribuir para que a condição de mulher } \\
\text { fique subjulgada à maternidade. }\end{array}$ & 6 \\
\hline $\begin{array}{l}\text { Bernardes et } \\
\text { al., } 2009^{26} \text {. }\end{array}$ & $\begin{array}{l}\text { Refletir, à luz da } \\
\text { bioética, sobre } \\
\text { a alocação de } \\
\text { recursos públicos } \\
\text { para a assistência à } \\
\text { saúde das pessoas } \\
\text { com deficiência. }\end{array}$ & $\begin{array}{l}\text { Artigo de opinião. São } \\
\text { discutidos referenciais } \\
\text { teóricos e legislações. }\end{array}$ & $\begin{array}{l}\text { Dada a sua vulnerabilidade, pessoas com } \\
\text { deficiência devem ser protegidas pelo Estado. } \\
\text { Há a necessidade de implementação de } \\
\text { políticas públicas para garantir o acesso desta } \\
\text { população aos serviços de saúde. }\end{array}$ & 7 \\
\hline $\begin{array}{l}\text { Cavalcante } \\
\text { e Goldson, } \\
2009^{27} \text {. }\end{array}$ & $\begin{array}{l}\text { Discutir o ciclo e a } \\
\text { cultura da pobreza } \\
\text { e sua interface com } \\
\text { a violência e os } \\
\text { maus tratos contra } \\
\text { crianças e jovens } \\
\text { com deficiência na } \\
\text { América Latina e } \\
\text { Caribe. }\end{array}$ & $\begin{array}{l}\text { Artigo de opinião. Trata } \\
\text { de questões relacionadas } \\
\text { a pobreza e violência } \\
\text { em crianças e jovens } \\
\text { deficientes na América } \\
\text { Latina e Caribe. }\end{array}$ & $\begin{array}{l}\text { A pobreza influencia negativamente o acesso à } \\
\text { escolaridade, saúde e emprego. Também atinge } \\
\text { indivíduos com deficiência, fruto em grande } \\
\text { parte de uma sucessão de exclusões, estigmas } \\
\text { e uma vida marginalizada, culminando num } \\
\text { ciclo deficiência-pobreza-deficiência. Há } \\
\text { poucos dados sobre maus tratos a deficientes } \\
\text { no Brasil. Medidas como suporte econômico } \\
\text { e melhoria dos sistemas de saúde e educação, } \\
\text { são fundamentais para diminuir a relação } \\
\text { entre pobreza, violência e maus tratos contra } \\
\text { os deficientes. }\end{array}$ & 7 \\
\hline Assis, $2009^{28}$. & $\begin{array}{l}\text { Debater o artigo } \\
\text { publicado por } \\
\text { Cavalcante e } \\
\text { Goldson, em } 2009 .\end{array}$ & $\begin{array}{l}\text { Artigo de opinião. A } \\
\text { autora debate a violência, } \\
\text { discutindo o artigo de } \\
\text { Cavalcante e Goldson }^{22} \text {. } \\
\text { Durante a discussão, } \\
\text { são apresentados dados } \\
\text { de estudo descritivo } \\
\text { realizado pelo grupo de } \\
\text { pesquisa ao qual a autora } \\
\text { pertence. }\end{array}$ & $\begin{array}{l}\text { Foi apresentado levantamento realizado no Rio } \\
\text { de Janeiro, com } 500 \text { crianças entre } 6 \text { e } 12 \text { anos, } \\
\text { do ensino público, através da aplicação de uma } \\
\text { versão abreviada do questionário 'Wechsler } \\
\text { Intelligence Scale for Children (WISC-III)' e } \\
\text { da avaliação de aspectos clínicos pelo 'Child } \\
\text { Behavior Checklist (CBCL)'. Uma pontuação } \\
\text { de QI menor que 70, caracterizando DI, foi } \\
\text { encontrada em 4\% das crianças. Todas as } \\
\text { crianças com DI vinham de famílias de baixo } \\
\text { nível socioeconômico, reforçando a ideia do } \\
\text { ciclo deficiência-pobreza-deficiência. }\end{array}$ & 7 \\
\hline
\end{tabular}

NE: nível de evidência, PNTN: Programa Nacional de Triagem Neonatal; PNI: Programa Nacional de Imunizações; DNV: Declaração de Nascido Vivo; ECLAMC: Estudo Colaborativo Latino-Americano de Malformações Congênitas; SIAT: Sistema de Informação sobre Agentes Teratogênico; SIEIM: Serviço de Informações sobre Erros Inatos do Metabolismo. 
Quadro 2. Categorização das legislações federais sobre políticas públicas de saúde para deficientes intelectuais no Brasil, no período entre 2002 e 2012.

\begin{tabular}{|c|c|c|}
\hline $\begin{array}{l}\text { Temas } \\
\text { abordados }\end{array}$ & Legislações & Descrição das legislações \\
\hline \multirow[t]{6}{*}{$\begin{array}{l}\text { Direito dos } \\
\text { deficientes }\end{array}$} & Decreto $186 / 2008$ & $\begin{array}{l}\text { Aprova o texto da Convenção sobre os Direitos das Pessoas com Deficiência e de seu } \\
\text { Protocolo Facultativo, assinados em Nova York, em } 30 \text { de março de } 2007 .\end{array}$ \\
\hline & Decreto $6.949 / 2009$ & $\begin{array}{l}\text { Promulga a Convenção Internacional sobre os Direitos das Pessoas com Deficiência e seu } \\
\text { Protocolo Facultativo, assinados em Nova York, em } 30 \text { de março de } 2007 .\end{array}$ \\
\hline & Decreto $7.612 / 2011$ & $\begin{array}{l}\text { Institui o Plano Nacional dos Direitos da Pessoa com Deficiência - Plano Viver sem } \\
\text { Limite. }\end{array}$ \\
\hline & Resolução 34/2005 & $\begin{array}{l}\text { Dispõe sobre a instauração de Comissão Provisória de Análise de Proposta de Anteprojeto } \\
\text { de Lei do Estatuto da Pessoa com Deficiência. }\end{array}$ \\
\hline & Portaria $1.060 / 2002$ & Institui a Política Nacional de Saúde da Pessoa Portadora de Deficiência. \\
\hline & Portaria 2/2012 & $\begin{array}{l}\text { Institui o Protocolo Nacional Conjunto para Proteção Integral a Crianças e Adolescentes, } \\
\text { Pessoas Idosas e Pessoas com Deficiência em Situação de Riscos e Desastres. }\end{array}$ \\
\hline $\begin{array}{l}\text { Prioridade } \\
\text { no } \\
\text { atendimento } \\
\text { de deficientes }\end{array}$ & Decreto $5.296 / 2004$ & $\begin{array}{l}\text { Regulamenta as Leis nos } 10.048 \text {, de } 8 \text { de novembro de } 2000 \text {, que dá prioridade de } \\
\text { atendimento às pessoas que especifica, e } 10.098 \text {, de } 19 \text { de dezembro de } 2000 \text {, que } \\
\text { estabelece normas gerais e critérios básicos para a promoção da acessibilidade das pessoas } \\
\text { portadoras de deficiência ou com mobilidade reduzida, e dá outras providências. }\end{array}$ \\
\hline \multirow{3}{*}{$\begin{array}{l}\text { Atenção ao } \\
\text { transtorno } \\
\text { autista }\end{array}$} & Lei $12.764 / 2012$ & $\begin{array}{l}\text { Institui a Política Nacional de Proteção dos Direitos da Pessoa com Transtorno do } \\
\text { Espectro Autista. }\end{array}$ \\
\hline & Portaria $1.635 / 2002$ & $\begin{array}{l}\text { Considerando a necessidade de garantir às pessoas portadoras de deficiência mental e } \\
\text { de autismo assistência por intermédio de equipe multiprofissional e multidisciplinar, } \\
\text { inclui no Sistema de Informações Ambulatoriais do Sistema Único de Saúde - SIA-SUS } \\
\text { procedimentos de avaliação, estimulação e orientação relacionadas ao desenvolvimento } \\
\text { da pessoa portadora de deficiência mental ou com autismo (máximo } 20 \text { procedimentos/ } \\
\text { paciente/mês). }\end{array}$ \\
\hline & Portaria $3.211 / 2007$ & $\begin{array}{l}\text { Constitui o Grupo de Trabalho (GT) sobre Atenção aos Autistas na Rede do Sistema } \\
\text { Único de Saúde - SUS. }\end{array}$ \\
\hline \multirow[t]{4}{*}{$\begin{array}{l}\text { Reabilitação } \\
\text { de deficientes }\end{array}$} & Lei $10.708 / 2003$ & $\begin{array}{l}\text { Institui o auxílio-reabilitação psicossocial para pacientes acometidos de transtornos } \\
\text { mentais egressos de internações. }\end{array}$ \\
\hline & Resolução 23/2004 & $\begin{array}{l}\text { Dispõe sobre a conclusão da Comissão Provisória para definir ações de habilitação e } \\
\text { reabilitação das pessoas portadoras de deficiência. }\end{array}$ \\
\hline & Resolução 32/2005 & $\begin{array}{l}\text { Dispõe sobre o encaminhamento ao Ministério da Saúde de solicitação de estudo e } \\
\text { providências para revisão e adequação dos procedimentos de reabilitação da pessoa } \\
\text { portadora de deficiência }\end{array}$ \\
\hline & Resolução 33/2005 & $\begin{array}{l}\text { Dispõe sobre a instauração de Comissão Provisória de Habilitação e Reabilitação de } \\
\text { Pessoas com Deficiência }\end{array}$ \\
\hline
\end{tabular}


Quadro 2. continuação

\begin{tabular}{|c|c|c|}
\hline $\begin{array}{c}\text { Temas } \\
\text { abordados }\end{array}$ & Legislações & Descrição das legislações \\
\hline $\begin{array}{l}\text { Denominação } \\
\text { dos deficientes }\end{array}$ & Resolução 1/2010 & $\begin{array}{l}\text { Altera dispositivos da Resolução no 35, de } 6 \text { de julho de 2005, que dispõe sobre o } \\
\text { Regimento Interno do Conade. Onde se lê "Pessoas Portadoras de Deficiência", leia-se } \\
\text { "Pessoas com Deficiência" }\end{array}$ \\
\hline \multirow{8}{*}{$\begin{array}{c}\text { Prevenção da } \\
\text { deficiência }\end{array}$} & Portaria $847 / 2002$ & Aprova o Protocolo clínico e diretrizes terapêuticas para fenilcetonúria. \\
\hline & Portaria $2.362 / 2005$ & $\begin{array}{l}\text { Reestrutura o Programa Nacional de Prevenção e Controle dos Distúrbios por Deficiência } \\
\text { de Iodo - DDI, designado por Pró-Iodo. }\end{array}$ \\
\hline & Portaria $71 / 2006$ & Aprova o Protocolo clínico e diretrizes terapêuticas - Hipoparatireoidismo \\
\hline & Portaria $1.315 / 2008$ & $\begin{array}{l}\text { Institui Comitê Nacional de Mobilização Social para Eliminação da Rubéola e da } \\
\text { Síndrome da Rubéola Congênita no Brasil }\end{array}$ \\
\hline & Portaria 14/2010 & Aprova o Protocolo clínico e diretrizes terapêuticas - Hipoparatireoidismo (atualização) \\
\hline & Portaria 56/2010 & Aprova o Protocolo clínico e diretrizes terapêuticas - Hipotireoidismo congênito. \\
\hline & Portaria $712 / 2010$ & Aprova o Protocolo clínico e diretrizes terapêuticas - Fenilcetonúria \\
\hline & Portaria $2.761 / 2010$ & $\begin{array}{l}\text { Aprova a Resolução GMC n 22, "Vigilância Epidemiológica e Controle de Enfermidades } \\
\text { Priorizadas e Surtos Entre os Estados-Partes do Mercosul" (Revogação das Resoluções } \\
\text { GMC n 50/99, 08/00, 04/01, 31/02 e 17/05) - Trata da Rubéola Congênita }\end{array}$ \\
\hline \multirow[t]{7}{*}{$\begin{array}{l}\text { Ações em } \\
\text { saúde para } \\
\text { deficientes }\end{array}$} & Decreto $7.988 / 2013$ & $\begin{array}{l}\text { Regulamenta os arts. } 1^{\circ} \text { a } 13 \text { da Lei no } 12.715 \text {, de } 17 \text { de setembro de 2012, que dispõem } \\
\text { sobre o Programa Nacional de Apoio à Atenção Oncológica - PRONON e o Programa } \\
\text { Nacional de Apoio à Atenção da Saúde da Pessoa com Deficiência - PRONAS/PCD. }\end{array}$ \\
\hline & Lei $12.715 / 2012$ & $\begin{array}{l}\text { Institui o Programa Nacional de Apoio à Atenção da Saúde da Pessoa com Deficiência - } \\
\text { PRONAS/PCD }\end{array}$ \\
\hline & Portaria $2.672 / 2011$ & $\begin{array}{l}\text { Institui o Comitê Nacional de Assessoramento e Apoio às Ações de Saúde do Plano } \\
\text { Nacional de para Pessoas com Deficiência. }\end{array}$ \\
\hline & Portaria $793 / 2012$ & $\begin{array}{l}\text { Institui a Rede de Cuidados à Pessoa com Deficiência no âmbito do Sistema Único de } \\
\text { Saúde. }\end{array}$ \\
\hline & Portaria $1.330 / 2012$ & $\begin{array}{l}\text { Aprova as Diretrizes de Atenção à Pessoa com Lesão Medular no âmbito do Sistema } \\
\text { Único de Saúde (SUS). }\end{array}$ \\
\hline & Portaria $1.432 / 2012$ & $\begin{array}{l}\text { Habilita Centros de Atenção Psicossocial para realizar procedimentos específicos previstos } \\
\text { na Tabela de Procedimentos, Medicamentos, Órteses e Próteses e Materiais Especiais do } \\
\text { Sistema Único de Saúde (SUS) }\end{array}$ \\
\hline & Portaria $2.809 / 2012$ & $\begin{array}{l}\text { Estabelece a organização dos Cuidados Prolongados para retaguarda à Rede de Atenção } \\
\text { às Urgências e Emergências (RUE) e às demais Redes Temáticas de Atenção à Saúde no } \\
\text { âmbito do Sistema Único de Saúde (SUS). }\end{array}$ \\
\hline \multirow[t]{2}{*}{$\begin{array}{c}\text { Triagem } \\
\text { neonatal }\end{array}$} & Portaria $1.434 / 2012$ & $\begin{array}{l}\text { Inclui na tabela de habilitação do Sistema do Cadastro Nacional de Estabelecimentos de } \\
\text { Saúde -SCNES a habilitação referente à fase IV do PNTN. }\end{array}$ \\
\hline & Portaria $2.829 / 2012$ & $\begin{array}{l}\text { Inclui a Fase IV no Programa Nacional de Triagem Neonatal (PNTN), instituído pela } \\
\text { Portaria } \text { nº }^{\circ} 22 / \mathrm{GM} / \mathrm{MS} \text {, de } 6 \text { de junho de } 2001 \text {. }\end{array}$ \\
\hline
\end{tabular}




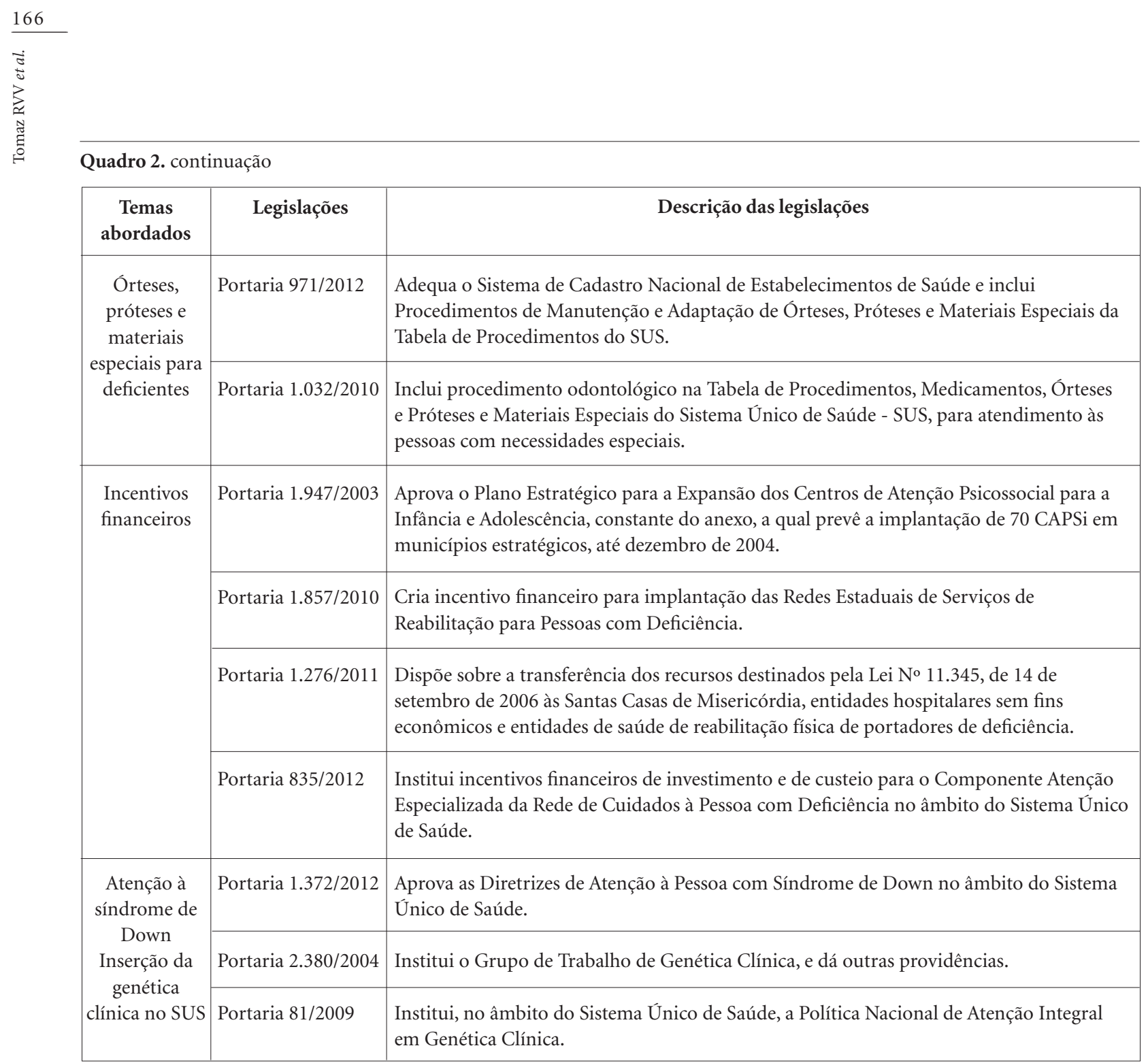

No Brasil, o Decreto legislativo ${ }^{\circ} 186$ de $2008^{30}$, aprovou o texto dessa Convenção, promulgado em 2009, por meio do Decreto no $6.949^{31}$. Estes Decretos trazem importantes considerações acerca do papel governamental brasileiro na proteção e no cuidado de deficientes e abordam também a questão da violência. Especificamente, designam que é dever do Estado a tomada de medidas de natureza legislativa, administrativa, social e educacional para a proteção contra todas as formas de violência, tortura, tratamentos cruéis, exploração e abuso das pessoas com deficiência, dentro e fora do lar, devendo atuar também sobre prevenção destas situações. Cabe ainda ao Estado promover a recuperação física, cognitiva e psicológica do deficiente que houver sofrido abusos, em ambientes que promovam o bem estar, a dignidade e a autonomia.

\section{Saúde mental}

A interface entre DI e psiquiatria é tema de discussão acalorada na literatura científica, com alguns autores a incluindo no escopo das desordens neuropsiquiátricas ${ }^{14}$. O DSM-V concebe a expressão "transtorno do desenvolvimento intelectual", incluindo a DI no segmento dos transtornos do neurodesenvolvimento, conjuntamente com outras condições como os motores, de comunicação e de aprendizagem, os de espectro do autismo e os de déficit de atenção e hiperatividade; sendo que essas outras condições podem, inclusive, ocorrer em concomitância com a DI ${ }^{32}$. Além disso, os transtornos mentais (em especial depressão, transtorno bipolar, transtornos de ansiedade e transtorno obsessivo-compulsivo) são comorbidades comuns entre deficientes intelectuais ${ }^{33}$. 
A IV Conferência Nacional de Saúde Mental reforça o elo entre políticas de saúde mental e DI no Brasil, ao trazer em seu relatório final algumas propostas direcionadas ao atendimento dos deficientes intelectuais, tais como realização de censo epidemiológico de agravos em saúde mental e deficiências intelectuais, ampliação da política de assistência social para deficientes intelectuais, além de preparação e capacitação das equipes dos CAPS Infatojuvenis (CAPSi) para atendimento de quadros como DI, autismo e síndrome de Down, comumente associados ao transtorno mental ${ }^{34}$. Esse documento parece indicar o início de um movimento de aproximação dos campos da saúde mental e da DI no país ${ }^{9}$.

Apesar das dificuldades para a realização de estudos epidemiológicos, pesquisadores apontam prevalência entre 30 e $40 \%$ de transtornos mentais entre deficientes intelectuais ${ }^{9,33}$. Interessante observar que quanto mais severa a DI, mais difícil é avaliar os sintomas psicopatológicos dos pacientes; por outro lado, nas situações de DI leve, alguns padrões de comportamentos comuns, como a existência de amigos imaginários e falar sozinho, são por vezes erroneamente identificados como sintomas psicopatológicos e medicalizados sem nenhuma indicação que justifique tal abordagem ${ }^{9}$. Outro aspecto importante é que, diante da DI, muitas vezes o transtorno mental e o sofrimento que advém dele são banalizados ${ }^{9,33}$.

Ainda com relação à interface entre saúde mental e DI, é relevante salientar os resultados de dois censos brasileiros, realizados em hospitais psiquiátricos nos Estados do Rio de Janeiro ${ }^{35} \mathrm{e}$ São Paulo ${ }^{36}$, que apontam os deficientes intelectuais como o segundo grupo de moradores mais frequente dessas instituições, sendo superados apenas por indivíduos com diagnóstico de transtornos psicóticos.

Os campos da saúde mental e da DI tornam a se encontrar quando se discute os Transtornos de Espectro do Autismo (TEA), fenômeno alvo de compreensões tanto no escopo das desordens mentais e comportamentais, quanto dos transtornos do neurodesenvolvimento. De 50 a 150 crianças na idade escolar, 1 apresenta TEA e estima-se que $75 \%$ destas tenham algum grau de $\mathrm{DI}^{37,38}$. Por outro lado, pelo menos $10 \%$ dos indivíduos com DI preenchem critérios clínicos compatíveis com diagnóstico simultâneo de TEA $^{38}$. No Brasil, desde 2012, a Política Nacional de Proteção dos Direitos da Pessoa com Transtorno do Espectro Autista considera a pessoa com TEA como uma alguém com deficiência, para todos os efeitos legais ${ }^{39}$.
Nas discussões sobre as políticas de saúde mental infantil, autores defendem a importância da intersetorialidade no tratamento, envolvendo o trabalho em saúde multiprofissional, como o desenvolvido nos CAPSi e em outros cenários de atenção primária à saúde, assim como a atuação das áreas de assistência social, educação e justiça, com a finalidade de garantir uma rede de cuidado ampliada ${ }^{20}$. Nesse sentido, em 2003 foi aprovada a Portaria no 1.947 , que trata da aplicação de recursos financeiros destinados à expansão dos CAPSi. Essa Portaria reconhece que a clientela típica dos CAPSi são crianças e adolescentes com transtornos mentais severos, incluindo autismo e DI com comorbidade psiquiátrica ${ }^{40}$.

No Brasil, apesar da literatura apontar que pessoas com DI são clientela comum das instituições de saúde mental ${ }^{7,9,35,36}$ e embora coexistam políticas públicas nos dois campos, parece haver pouca articulação e diálogo entre as diferentes redes de apoio das duas áreas. $\mathrm{O}$ reconhecimento da vulnerabilidade a problemas de saúde mental em indivíduos com DI é essencial para assegurar um cuidado integral e adequado a essa população $\mathrm{O}^{7,9,33,41}$. A aplicação efetiva de uma rede intersetorial de apoio ao deficiente intelectual com transtorno mental permanece como um desafio a ser superado, dado o grau de complexidade operacional e de articulação necessária.

\section{Ética}

Nas últimas décadas, houve mudanças na percepção da sociedade brasileira com relação aos deficientes, passando de uma visão depreciativa, cujas motivações para atenção eram basicamente assistencialistas, caritativas ou religiosas, para outra integradora, que enxerga nos deficientes competências e direitos à participação social ${ }^{26}$.

É dever do Estado fornecer condições para o desenvolvimento dos deficientes, tanto contribuindo para acesso facilitado a setores básicos (educação, saúde, trabalho e lazer), como realizando investimentos necessários à prestação de serviços de qualidade. Na aplicação dos investimentos, há de se considerar questões éticas e de justiça, direcionando ações e recursos aos indivíduos mais vulneráveis e com maiores necessidades, preservando a equidade.

Seis legislações relacionadas a direitos dos deficientes foram identificadas nesta revisão, inclusive a Política Nacional de Saúde da Pessoa Portadora de Deficiência, de 20024. Outras legislações importantes, como aquelas que aprovam e promulgam o texto da Convenção sobre 
os Direitos das Pessoas com Deficiência ${ }^{30,31}$, que institui o Plano Nacional dos Direitos da Pessoa com Deficiência ${ }^{42}$ e as discussões sobre a Lei do Estatuto da Pessoa com Deficiência ${ }^{43}$, representam um avanço no debate de políticas públicas direcionadas aos deficientes intelectuais.

Profissionais de saúde devem atuar no processo de inclusão, contribuindo para que o deficiente desenvolva autonomia e conheça seus direitos ${ }^{23}$. É importante reconhecer as potencialidades existentes nos deficientes intelectuais, procurando não assumir posições superprotetoras ${ }^{26}$. Estudo qualitativo, realizado por meio de entrevistas com 21 médicos de diferentes especialidades que trabalhavam com crianças com doenças genéticas associadas a malformações congênitas e DI, observou que estes supervalorizavam a figura materna, como alguém merecedora do título de "heroína", com consequente "invisibilidade" do deficiente ${ }^{25}$.

Esta revisão identificou uma legislação específica sobre denominação dos deficientes - Resolução $1 / 2010^{44}$, que dispõe sobre o regimento interno do Conselho Nacional dos Direitos da Pessoa com Deficiência e que propõe que a expressão "pessoas portadoras de deficiência" seja substituída por "pessoas com deficiência”. Tal alteração remonta a um antigo debate sobre como descrever a deficiência e o deficiente. A linguagem referente ao tema pode estar carregada de violência e de eufemismos discriminatórios ${ }^{45}$. Em consonância com recomendações internacionais, expressões como "pessoa portadora de deficiência" ou "pessoa com necessidades especiais" têm sido abandonadas. Há entendimento de que a condição de ter uma deficiência faz parte da existência individual - o indivíduo não porta sua deficiência, ele tem uma deficiência, que o constitui como sujeito. Assim, tanto o verbo "portar" como o substantivo ou o adjetivo "portadora" não se aplicam a uma condição inata ou adquirida que faz parte da pessoa.

\section{Necessidades de saúde}

No Brasil, não há priorização de políticas públicas de saúde para deficientes intelectuais, fato evidenciado a partir da constatação de que nenhuma das desenvolvidas em atenção às pessoas deficientes é direcionada exclusivamente a esse grupo $^{17}$.

Nesta revisão, observou-se a existência de legislações que contemplam demandas particulares da população com DI, através, por exemplo, de procedimentos odontológicos ${ }^{46}$, serviços de reabilitação ${ }^{47-49}$, e instituição da rede de cuidados à pessoa com deficiência no âmbito do SUS ${ }^{50}$. Contudo, há insuficiência de informações sobre o exercício desses direitos legais.

O foco das políticas públicas de saúde de muitos países em relação à DI é a prevenção, quando é necessário também promover o bem estar dos deficientes, através do cuidado de suas demandas de saúde específicas ${ }^{21}$.

Segundo a "International Association for the Scientific Study of Intellectual Disabilities" (IASSID), fazem parte das demandas de saúde 15 itens que acometem grande parcela dos indivíduos com DI: (1) saúde bucal, (2) visão, (3) nutrição, (4) constipação intestinal crônica, (5) epilepsia, (6) problemas tireoidianos, (7) distúrbios neurocomportamentais, (8) refluxo gastroesofágico e Helicobacter pylori, (9) osteoporose, (10) medicações em geral, (11) imunizações, (12) atividades físicas, (13) etiologia/genética, (14) saúde integral e (15) saúde da mulher. Há diversas barreiras para a implantação de políticas de saúde que contemplem esses 15 aspectos, como falta de conhecimento entre profissionais de saúde e cuidadores, atitudes sociais negativas e dificuldades de comunicação entre os vários setores envolvidos no cuidado ao deficiente. Ações como rastreamento de demandas de saúde, qualificação de cuidadores, incentivo a hábitos saudáveis e atitudes de autocuidado, incremento à qualidade e quantidade de trabalhadores da saúde e melhorias de comunicação entre setores públicos, são ferramentas importantes para o atendimento dessas necessidades ${ }^{21}$.

Capacitação contínua de profissionais de saúde e formação de equipes multiprofissionais são propostas das Conferências Nacionais sobre os Direitos da Pessoa com Deficiência. Idealmente, essa capacitação deve se iniciar antes mesmo da práxis cotidiana, com a discussão sobre a deficiência durante o período de formação educacional dos profissionais.

\section{Promoção de saúde e prevenção de agravos}

O Brasil instituiu em 2011 o "Plano Viver sem Limite" 42 , cuja finalidade é assegurar o exercício de direitos aos deficientes. Entre as diretrizes desse Plano, encontram-se a prevenção das deficiências, além da amplificação e qualificação da rede de atenção à saúde, uma importante ação de promoção. Em 2012, foi instituído o Programa Nacional de Apoio à Atenção da Saúde da Pessoa com Deficiência ${ }^{51}$, que tem como objetivo a captação de recursos para a prevenção, a promoção, 
o diagnóstico, o tratamento e a reabilitação do deficiente.

Também importantes no contexto brasileiro são as iniciativas desenvolvidas com relação aos defeitos congênitos. As ações governamentais, previstas e subsidiadas pelas leis nacionais, incluem o Programa Nacional de Triagem Neonatal, a obrigatoriedade da fortificação das farinhas de trigo e milho com ácido fólico a partir de 2004, e a luta contra a rubéola congênita através do Programa Nacional de Imunizações ${ }^{18}$. Somam-se às estratégias governamentais desenvolvidas por grupos técnicos e de pesquisa, como as elaboradas pelo Serviço de Genética Médica do Hospital de Clínicas de Porto Alegre da Universidade Federal do Rio Grande do Sul, através do Sistema de Informação sobre Agentes Teratogênicos e do Serviço de Informações sobre Erros Inatos do Metabolismo ${ }^{18}$.

É inegável a importância das ações de promoção em saúde desenvolvidas por entidades presentes na comunidade civil, como as APAE. Além de propiciarem formação educacional e de trabalharem na inclusão, o acesso a esses serviços promove a redução do estresse materno, por meio da interação com outras crianças deficientes, e melhor entendimento da situação.

Em 2014, o Ministério da Saúde instituiu a Política Nacional de Atenção Integral às Pessoas com Doenças Raras, que propõe uma linha de cuidado específica para $\mathrm{DI}^{10}$, gerando perspectivas positivas em pacientes, famílias e cuidadores. Acesso aos serviços de saúde de diferentes complexidades, atendimento de qualidade por equipe multiprofissional, pesquisa diagnóstica e tratamento adequado, quando desempenhados corretamente, são ferramentas de promoção e prevenção, e fazem parte das demandas em saúde dos deficientes intelectuais.

\section{Considerações finais}

A Política Nacional de Saúde para Pessoa com Deficiência, de 2002, traz como demandas a necessidade de inclusão, reabilitação, promoção de saúde e prevenção de agravos para população deficiente; ações dependentes da articulação entre diferentes setores governamentais e da participação da sociedade civil. Nesta pesquisa, foram encontradas legislações no campo da saúde que visam ao atendimento das principais diretrizes recomendadas por essa Política, embora faltem estudos que abordem a efetividade das legislações propostas e seu nível de implantação.
Do ponto de vista científico, observou-se que, no Brasil, as discussões sobre as questões de saúde pública para a população com DI são pouco específicas, sendo majoritariamente tratadas em meio a reflexão com os demais tipos de deficiências, ou em concomitância com outros países de realidade econômica semelhante. As poucas pesquisas publicadas nos últimos anos abordam aspectos relacionados à condição socioeconômica, violência, saúde mental, ética, necessidades de saúde, promoção e prevenção da saúde.

Novas pesquisas devem reconhecer e valorizar as particularidades de atenção à saúde dessa população. Sugere-se o desenvolvimento de investigações sobre as ações de equipes multiprofissionais e a contribuição dos diversos atores órgãos governamentais, organizações não governamentais, serviços especializados, comunidade e família - na melhoria da qualidade de vida e assistência às pessoas com DI. O incremento de pesquisas na área é uma demanda da própria população deficiente e permitirá conhecer suas necessidades de saúde específicas, além de oferecer embasamento sólido em questões essenciais, como prevenção, promoção, diagnóstico e tratamento.

No Brasil, na última década, foram estabelecidas algumas políticas públicas voltadas aos deficientes intelectuais, inclusive na área da saúde. Contudo, a implementação e a garantia efetiva dos direitos assegurados por lei, a alocação de recursos e o desenvolvimento de redes de assistência e de proteção específicas e efetivas, permanecem como desafios a serem superados.

\section{Colaboradores}

RVV Tomaz planejou e elaborou o projeto de pesquisa, coletou e analisou os dados, trabalhou na interpretação dos resultados, na redação e na revisão final do manuscrito. TL Rosa e DB Van contribuíram substancialmente com a coleta e análise dos dados, trabalharam na interpretação dos resultados, na redação e na revisão final do manuscrito. DG Melo concebeu e coordenou o projeto de pesquisa, orientou a coleta e análise dos dados, trabalhou na interpretação dos resultados, na redação e na revisão final do manuscrito. 


\section{Agradecimentos}

À Fundação de Amparo à Pesquisa do Estado de São Paulo (FAPESP), pelo apoio financeiro a RVV Tomaz.

\section{Referências}

1. American Psychiatric Association. Diagnostic and Statistical Manual of Mental Disorders - DSM-IV-TR. Washington: American Psychiatric Association; 2000.

2. Schalock RL, Borthwick-Duffy SA, Bradley VJ, Buntinx WHE, Coulter DL, Craig EM, Gomez SC, Lachapelle Y, Luckasson R, Reeve A, Shogren KA, Snell ME, Spreat S, Tassé MJ, Thompson JR, Verdugo-Alonso MA, Wehmeyer ML, Yeager MH. Intellectual Disability: Definition, Classification, and Systems of Supports. $11^{\mathrm{a}} \mathrm{ed}$. Washington: American Association on Intellectual and Developmental Disabilities; 2010.

3. Brasil. Instituto Brasileiro de Geografia e Estatística (IBGE). Censo Demográfico 2010 [Internet]. [acessado 2014 mar 29]. Disponível em: http://www.ibge.gov.br/ home/estatistica/populacao/censo2010/default.shtm

4. Brasil. Ministério da Saúde. Gabinete do Ministro. Portaria n. ${ }^{\circ} 1.060$ de 05 de Junho de 2002. Política Nacional de Saúde da Pessoa Portadora de Deficiência. Diário Oficial da União 2002; 5 jun.

5. Brasil. Presidência da República. Secretaria Nacional de Promoção dos Direitos da Pessoa com Deficiência. Secretaria de Direitos Humanos da Presidência da República. Avanços das Políticas Públicas para as Pessoas com Deficiência: Uma Análise a partir das Conferências Nacionais. Brasília: Presidência da República; 2012.

6. Brasil. Secretaria de Direitos Humanos da Presidência da República (SDH/PR), Secretaria Nacional de Promoção dos Direitos da Pessoa com Deficiência (SNPD), Conselho Nacional dos Direitos da Pessoa com Deficiência (Conade). III Conferência Nacional dos Direitos da Pessoa com Deficiência - Relatório Final. Brasília: SDH, SNPD, Conade; 2013.

7. Surjus LTLS, Campos RTO. Deficiência Intelectual e Saúde Mental: Quando a Fronteira Vira Território. Rev Polis e Psique 2013; 3(2):82-96.

8. Federação Nacional das APAE. [Internet]. Rede APAE e sua história. [acessado 2014 nov 23]. Disponível em: http://www.apaebrasil.org.br

9. Surjus LTLS, Campos RTO. Interface entre Deficiência Intelectual e Saúde Mental: revisão hermenêutica. Rev Saude Publica 2014; 48(3):532-540.

10. Brasil. Ministério da Saúde. Gabinete do Ministro. Portaria n. 199 de 30 de Janeiro de 2014. Institui a Política Nacional de Atenção Integral às Pessoas com Doenças Raras, aprova as Diretrizes para Atenção Integral às Pessoas com Doenças Raras no âmbito do Sistema Único de Saúde (SUS) e institui incentivos financeiros de custeio. Diário Oficial da União 2014; 12 fev.

11. Brasil. Ministério da Saúde (MS). Departamento de Gestão e Incorporação de Tecnologias em Saúde da Secretaria de Ciência, Tecnologia e Insumos Estratégicos - DGITS/SCTIE. Comissão Nacional de Incorporação de Tecnologias no SUS (CONITEC). Relatório $n^{\circ} 109$ - Procedimentos Laboratoriais para Diagnóstico de Doenças Raras. Brasília: MS; 2013.

12. The World Bank. [Internet]. World Development Indicators. [acessado 2014 mar 29]. Disponível em: http:// data.worldbank.org/country/brazil

13. Melnyk BM, Fineout-Overholt E. Making the case for evidence-based practice. In: Melnyk BM, Fineout-Overholt E. Evidence-based practice in nursing \& healthcare. A guide to best practice. Philadelphia: Lippincot Williams \& Wilkins; 2005. p. 3-24. 
14. Patel V, Araya R, Chatrerjee S, Chisholm D, Cohen A, Silva MD, Hosman C, McGuire H, Rojas G, Ommeren MV. Treatment and prevention of mental disorders in low-income and middle-income countries. Lancet 2007; 370(9591):991-1005.

15. Maulik PA, Darmstadt GL. Childhood Disability in Low- and Middle-Income Countries: Overview of Screening, Prevention, Services, Legislation, and Epidemiology. Pediatrics 2007; 120(1):1-57.

16. França ISX, Pagliuca LMF, Baptista RS. Política de inclusão do portador de deficiência: possibilidades e limites. Acta Paul Enferm 2008; 21(1):112-116.

17. Mercadante MT, Evans-Lacko S, Paula CS. Perspectives of intellectual disability in Latin American countries: epidemiology, policy, and services for children and adults. Curr Opin Psychiatry 2009; 22(5):469-474.

18. Horovitz DDG, Llerena JC, Mattos RA. Atenção aos defeitos congênitos no Brasil: panorama atual. Cad Saude Publica 2005; 21(4):1055-1064.

19. Patel V. Mental health in low- and middle-income countries. British Medical Bulletin 2007; 81-82:81-96.

20. Couto MCV, Duarte CS, Delgado PGG. Child mental health and Public Health in Brazil: current situation and challenges. Rev. Bras. Psiquiatr 2008; 30(4):384389.

21. Frey GC, Temple VA. Health promotion for Latin Americans with intellectual disabilities. Salud Publica Mex 2008; 50(Supl. 2):167-177.

22. Horovitz DDG, Cardoso MHCA, Llerena JC, Mattos RA. Atenção aos defeitos congênitos no Brasil: características do atendimento e propostas para formulação de políticas públicas em genética clínica. Cad Saude Publica 2006; 22(12):2599-2609.

23. Aragão AEA, Ponte KMA, Pagliuca LMF, Silva MAM, Ferreira AGN, Sousa PCP. Perfil das pessoas com deficiência de uma paróquia da Diocese de Sobral - Ceará: um estudo quantitativo. Online Brazilian Journal of Nursing 2010; 9(1).

24. Cavalcante FG, Marinho ASN, Bastos OM, Deus VV, Maimone MS, Carvalho MM, Fiaux MP, Valdene RSR. Diagnóstico situacional da violência contra crianças e adolescentes com deficiência em três instituições do Rio de Janeiro. Cien Saude Colet 2009; 14(1):45-56.

25. Martins AJ, Cardoso MHCA, Llerena JC, Moreira MCN. A concepção de família e religiosidade presente nos discursos produzidos por profissionais médicos acerca de crianças com doenças genéticas. Cien Saude Colet 2012; 17(2):545-553.

26. Bernardes LCG, Maior IMML, Spezia CH, Araújo TCCF. Pessoas com deficiência e políticas de saúde no Brasil: reflexões bioéticas. Cien Saude Colet 2009; 14(1):31-38

27. Cavalcante FG, Goldson E. Situational analysis of poverty and violence among children and youth with disabilities in the Americas - an agenda proposal. Cien Saude Colet 2009; 14(1):7-20.

28. Assis SG. Children and youth with and without disabilities. Cien Saude Colet 2009; 14(1):21-29.

29. Brasil. Presidência da República. Casa Civil. Subchefia para Assuntos Jurídicos. Lei n. ${ }^{\circ} 8.742$ de 7 de Dezembro de 1993. Dispõe sobre a organização da Assistência Social e dá outras providências. Diário Oficial da União 1998; $8 \mathrm{dez}$
30. Brasil. Congresso Nacional. Decreto n. ${ }^{\circ} 186$ de 9 de Julho de 2008. Aprova o texto da Convenção sobre os Direitos das Pessoas com Deficiência e de seu Protocolo Facultativo, assinados em Nova Iorque, em 30 de março de 2007. Diário Oficial da União 2008; 10 jul.

31. Brasil. Presidência da República. Casa Civil. Subchefia para Assuntos Jurídicos. Decreto n. ${ }^{\circ} 6.949$ de 25 de Agosto de 2009. Promulga a Convenção Internacional sobre os Direitos das Pessoas com Deficiência e seu Protocolo Facultativo, assinados em Nova York, em 30 de março de 2007. Diário Oficial da União 2009; 26 ago.

32. American Psychiatric Association. Diagnostic and Statistical Manual of Mental Disorders - DSM-V-TR. Washington: American Psychiatric Association; 2013.

33. Cooper SA, Smiley E, Morrison J, Williamson A, Allan L. Mental ill-health in adults with intellectual disabilities: prevalence and associated factors. Br J Psychiatry. 2007; 190:27-35.

34. Brasil. Ministério da Saúde (MS). Conselho Nacional de Saúde. Relatório Final da IV Conferência Nacional de Saúde Mental - Intersetorial. Brasília: Conselho Nacional de Saúde, MS; 2010.

35. Gomes MPC, Couto MCV, Pepe VLE, Almeida LM, Delgado PGG, Coutinho ESF. Censo dos pacientes internados em uma instituição asilar no Estado do Rio de Janeiro: dados preliminares. Cad Saude Publica 2002; 18(6):1803-1807.

36. Barros S, Bichaff R. Desafios para a desinstitucionalização: censo psicossocial dos moradores em hospitais psiquiátricos do Estado de São Paulo. São Paulo: FUNDAP, Secretaria de Estado da Saúde; 2008.

37. Mefford HC, Batshaw ML, Hoffman EP. Genomics, intellectual disability, and autism. N Engl J Med 2012; 366(8):733-743.

38. Srivastava AK, Schwartz CE. Intellectual disability and autism spectrum disorders: Causal genes and molecular mechanisms. Neurosci Biobehav Rev 2014; 46(2):161-174.

39. Brasil. Presidência da República. Casa Civil. Subchefia para Assuntos Jurídicos. Lei n. 12.764 de 27 de Dezembro de 2012. Institui a Política Nacional de Proteção dos Direitos da Pessoa com Transtorno do Espectro Autista; e altera o $\$ 3^{\circ}$ do art. 98 da Lei no 8.112 , de 11 de dezembro de 1990. Diário Oficial da União 2012; $28 \mathrm{dez}$.

40. Brasil. Ministério da Saúde. Gabinete do Ministro. Portaria n. ${ }^{\circ} 1.947$ de 10 de Outubro de 2003. Aprovar o Plano Estratégico para a Expansão dos Centros de Atenção Psicossocial para a Infância e Adolescência, constante do anexo, a qual prevê a implantação de 70 CAPSi em municípios estratégicos, até dezembro de 2004. Diário Oficial da União 2003; 13 out.

41. Bouras N, Holt G. Mental health services for adults with disabilities. Br J Psychiatry 2004; 184(4):291-292.

42. Brasil. Presidência da República. Casa Civil. Subchefia para Assuntos Jurídicos. Decreto n. ${ }^{\circ} 7.612$ de 17 de Novembro de 2011. Institui o Plano Nacional dos Direitos da Pessoa com Deficiência - Plano Viver sem Limite. Diário Oficial da União 2011; 18 nov. 
43. Brasil. Presidência da República. Secretaria Especial dos Direitos Humanos. Conselho Nacional do Direito da Pessoa Portadora de Deficiência. Resolução no 34 de 04 de Maio de 2005. Dispõe sobre a instauração de Comissão Provisória de Análise de Proposta de Anteprojeto de Lei do Estatuto da Pessoa com Deficiência. Diário Oficial da União 2005; 13 maio.

44. Brasil. Presidência da República. Secretaria Especial dos Direitos Humanos. Conselho Nacional do Direito da Pessoa Com Deficiência. Resolução no 1 de 15 de Outubro de 2010. Altera dispositivos da Resolução no 35 , de 6 de julho de 2005, que dispõe sobre o Regimento Interno do Conade. Onde se lê "Pessoas Portadoras de Deficiência", leia-se "Pessoas com Deficiência". Diário Oficial da União 2011; 22 fev.

45. Diniz D. O que é deficiência. São Paulo: Brasiliense; 2007. Coleção Primeiros Passos

46. Brasil. Ministério da Saúde. Gabinete do Ministro. Portaria n. ${ }^{\circ} 1.032$ de 05 de Maio de 2010. Inclui procedimento odontológico na Tabela de Procedimentos, Medicamentos, Órteses e Próteses e Materiais Especiais do Sistema Único de Saúde - SUS, para atendimento às pessoas com necessidades especiais. Diário Oficial da União 2010; 6 maio.

47. Brasil. Presidência da República. Secretaria Especial dos Direitos Humanos. Conselho Nacional do Direito da Pessoa Portadora de Deficiência. Resolução no 23 de 11 de Fevereiro de 2004. Dispõe sobre a conclusão da Comissão Provisória para definir ações de habilitação e reabilitação das pessoas portadoras de deficiência. Diário Oficial da União 2004; 11 fev.

48. Brasil. Presidência da República. Secretaria Especial dos Direitos Humanos. Conselho Nacional do Direito da Pessoa Portadora de Deficiência. Resolução no 32 de 13 de Abril de 2005. Dispõe sobre o encaminhamento ao Ministério da Saúde de solicitação de estudo e providências para revisão e adequação dos procedimentos de reabilitação da Pessoa Portadora de deficiência. Diário Oficial da União 2005; 18 abr.

49. Brasil. Presidência da República. Secretaria Especial dos Direitos Humanos. Conselho Nacional do Direito da Pessoa Portadora de Deficiência. Resolução no 33 de 13 de Abril de 2005. Dispõe sobre a instauração de Comissão Provisória de Habilitação e Reabilitação de Pessoas com Deficiência. Diário Oficial da União 2005; 20 abr.

50. Brasil. Ministério da Saúde. Gabinete do Ministro. Portaria n. 793 de 24 de Abril de 2012. Institui a Rede de Cuidados à Pessoa com Deficiência no âmbito do Sistema Único de Saúde. Diário Oficial da União 2012; 25 abr.

51. Brasil. Presidência da República. Casa Civil. Subchefia para Assuntos Jurídicos. Lei n. ${ }^{\circ} 12.715$ de 17 de Setembro de 2012. Institui o Programa Nacional de Apoio à Atenção da Saúde da Pessoa com Deficiência. Diário Oficial da União 2012; 19 set. 